\title{
A formação de professores para a Educação Inclusiva: alguns aspectos de um trabalho colaborativo entre pesquisadores e professores da Educação Infantil
}

Claudia Regina Mosca Giroto* Rosane Michelli de Castro**

\section{Resumo}

A fim de contribuir com a formação de professores da Educação Infantil para a Educação Inclusiva, neste artigo, tivemos como objetivo central descrever o modo como foi abordada a questão das dificuldades de aprendizagem e o impacto de um diagnóstico equivocado atribuído a uma criança em fase inicial de aprendizagem formal da escrita, em um dos encontros teórico-reflexivos empreendidos junto a 43 professores de classes de Pré II, de dez escolas municipais de Educação Infantil, de um município do interior do Estado de São Paulo. Tal descrição foi norteada pelas etapas da abordagem colaborativa consideradas no subprojeto "Compreensão acerca do diagnóstico clínico da Dislexia e seu impacto no futuro escolar da criança matriculada em classes de Pré ll da Educação Infantil", desenvolvido como uma das etapas do projeto maior denominado "Despatologização da aprendizagem da escrita e Educação Inclusiva: reflexões e ações do professor de Educação Infantil". Ao final, foi possível a identificação, mediante os relatos dos professores mencionados, da necessidade de ressignificação de suas vivências e experiências didáticas para a sistematização de novas ações direcionadas ao enfrentamento das dificuldades de aprendizagem que perpassam o processo de apropriação da escrita de parte dos alunos, o que poderá contribuir para a despatologização do ambiente escolar, na medida em que os professores poderão auxiliar seus alunos na construção de uma relação mais positiva com a escrita, em detrimento da adoção de procedimentos rígidos e restritos que não consideram a relação de cada sujeito com a escrita e as singularidades presentes em tal relação.

Palavras-chave: Educação; Formação de professores; Educação Inclusiva.

\section{Teacher's education for Inclusive Education: some aspects of a collaborative work between researchers and teachers of Childhood Education}

\section{Astract}

To contribute to formation of Childhood Education teachers for the Inclusive Education, this article had as its central objective describe how it was addressed the issue of learning difficulties and the impact of misdiagnosis assigned to a

\footnotetext{
* Professor Assistente Doutor - Departamento de Educação Especial da Faculdade de Filosofia e Ciências (FFC) Universidade Estadual Paulista (UNESP), Campus de Marília, São Paulo, Brasil. ** Professor Assistente Doutor - Departamento de Didática da Faculdade de Filosofia e Ciências (FFC), Universidade Estadual Paulista (UNESP), Campus de Marília, São Paulo, Brasil.
} 
child in the initial phase formal learning of writing, in one of the theoretical-reflective meetings undertaken with 43 teachers for Pre II, of the ten schools of Childhood Education of the state of São Paulo. Such a description was guided through the of the collaborative approach taken subproject "understanding about the clinical diagnosis of dyslexia and its impact on the educational future of children enrolled in classes II Pre Childhood education", developed as one of the phases and as part of larger project called "depathologization of the learning of the writing and Inclusive Education: Reflections and actions of the professor of Childhood Education". At the and, was possible the identification by the reports arising from the participation of teachers mentioned, the need to resignification their didactical experiences for the systematization of new actions aimed at coping with learning difficulties that pervade the process of appropriation writing of the students, which may contribute to depathologization of the school environment to the extent that teachers can assist students in building a more positive relationship with writing, rather than adopting rigid and restricted procedures that do not consider the relationship of each subject with writing and the singularities present in this relationship.

Keywords: Education; Teacher Education; Inclusive Education.

\section{Introdução}

Sob o paradigma da inclusão, ${ }^{1}$ o trabalho pedagógico de caráter inclusivo deve, necessariamente, ser diverso e adequado para garantir a aprendizagem de todos os alunos, por mais intensas que sejam as diferenças que caracterizam a diversidade da clientela do sistema educacional (BRASIL, 1997).

A operacionalização de uma pedagogia inclusiva, entretanto, é um processo bastante complexo por implicar a necessidade de se criar e de se garantir condições que oportunizem o acesso e a permanência de todos os alunos na escola, não apenas dos alunos com deficiência, mas de todos os que frequentam o sistema educacional inclusivo. Tais condições devem contemplar o uso de novos recursos e de tecnologias que favoreçam a apropriação dos conhecimentos valorizados culturalmente pela escola.

Nesse sentido, a atribuição de rótulos negativos à criança em processo de apropriação da linguagem escrita, considerada pelo professor, equivocadamente, como sendo aquela que apresenta distúrbio de aprendizagem, somada à atribuição de causas individuais e orgânicas localizadas na própria criança, pode determinar o que Moysés (2001) caracteriza como "medicalização da aprendizagem", que resulta, então, do processo de biologização da educação e do fracasso escolar.

A respeito da imposição de rótulos e de julgamentos acerca do desempenho escolar de crianças em processo de escolarização, Omote (1995, 
A formação de professores para a Educação Inclusiva: alguns aspectos de um trabalho colaborativo entre pesquisadores e professores da Educação Infantil

2000) ressalta que não é o rótulo, em si, que estigmatiza o indivíduo, mas o julgamento que as pessoas fazem a respeito desse indivíduo rotulado, muitas vezes a partir de características tidas como desviantes do padrão de normalidade imposto pela sociedade.

Nesse sentido, os rótulos atribuídos à criança-aluno, com base em expectativas e julgamentos emitidos por seu professor, podem se concretizar, se o professor tiver as piores expectativas sobre o aluno considerado como aquele que apresenta dificuldade de aprendizagem da leitura e escrita e se acreditar que esse aluno terá um péssimo desempenho escolar. Do mesmo modo, se o professor tiver as melhores expectativas a respeito de um aluno, poderá acreditar que esse aluno apresentará melhor desempenho escolar. Tais expectativas do professor caracterizam as "profecias autorrealizadoras", que podem, então, interferir no desempenho escolar de seus alunos positivamente, quando são julgados como bons alunos e, negativamente, quando as expectativas sobre eles são as piores (ROSENTHAL; JACOBSON, 1981). Essas "profecias autorrealizadoras" podem determinar, de acordo com Eizirick (1984), tanto a criação quanto a manutenção de rótulos, a ponto de contribuírem para a exclusão desses alunos do processo de escolarização e, consequentemente, do processo educacional inclusivo.

Sobre tal possibilidade de exclusão, Moysés (2001) chama a atenção para a condição que esses alunos podem vivenciar, visto que, ao esperar menos dos alunos considerados como sendo aqueles com distúrbios, o professor acabará por investir menos em sua aprendizagem. Isso pode repercutir também no comprometimento de aspectos relativos às relações de ensino e de aprendizagem, em sala de aula, e na autoestima dessas crianças, que passam a se considerar incapacitadas para a construção efetiva de práticas de leitura e de escrita e a incorporar tal incapacidade como característica própria e pessoal.

Moysés (2001) ressalta que, em decorrência do comprometimento desses aspectos, tais crianças sofrem o que ela denomina de "institucionalização invisível”, pois, mesmo que estas crianças permaneçam no espaço físico da sala de aula, são excluídas do processo de ensino e de aprendizagem.

Berberian $(2003,2004)$ chama a atenção para o fato de que a criança apontada como portadora de um distúrbio de aprendizagem terá, provavelmente, poucas condições de avançar no domínio da linguagem escrita, em um contexto escolar patologizador. De acordo com essa autora, é esse contexto que, frequentemente, possibilita a incorporação, por parte dessa criança, da condição de incapacidade que a leva a se desinteressar pelas práticas de leitura e escrita.

Desse modo, ocorre o deslocamento, na escola, da atenção coletiva, direcionada ao processo de apropriação da linguagem escrita, para o foco nos aspectos individuais e, consequentemente, no aluno, que passa a ser considerado como principal responsável pelo não-aprender. 
A "medicalização da aprendizagem" tem contribuído para que questões educacionais deixem de ser refletidas e solucionadas pelos profissionais da educação para ocuparem os profissionais da saúde, reforçando a ideia, entre os profissionais que atuam nessas duas áreas, de que o professor é desqualificado ou inadequadamente preparado para lidar com as dificuldades apresentadas por seus alunos durante o processo de escolarização (MOYSÉS; COLLARES, 1992; MOYSÉS, 2001). Tal ideia acaba por legitimar a atuação dos profissionais da saúde na escola (em grande parte igualmente despreparados) e, consequentemente, a patologização dessas dificuldades apresentadas por seus alunos, que, comumente, são características próprias do processo de apropriação formal da linguagem escrita e não representam sintomas de patologias (GIROTO, 2006).

A má formação profissional, nas áreas da educação e da saúde, tem sido apontada como um importante fator para a transformação de um processo saudável de aprendizagem em um processo marcado pelos erros, pelos distúrbios e pela estigmatização de crianças que, em razão das singularidades inerentes à forma como se relacionam com a linguagem escrita, acabam, então, sendo expropriadas das oportunidades de se constituírem como sujeito, por meio dessa modalidade de linguagem (MOYSÉS, 2001; GIROTO, 2006).

Ao ser levado em conta o paradigma atual sob o qual o Sistema Educacional tem construído as bases de suas reflexões e ações - o paradigma da inclusão -, uma vez que práticas assistencialistas, de segregação e de exclusão têm sido cada vez mais refutadas, é relevante considerar o papel assumido pelo professor da Educação Infantil no contexto da educação inclusiva.

Com base na concepção de inclusão que preconiza o acesso de todos a todas as oportunidades (ARANHA, 2000), o contexto educacional inclusivo passa a ter reforçada a necessidade de proporcionar respostas educativas que atendam às peculiaridades de cada aluno durante o seu processo de escolarização (OLIVEIRA; LEITE, 2000).

Sob essa perspectiva de educação inclusiva, o professor de Educação Infantil tem um destaque especial quanto ao acolhimento da criança que irá se deparar com propostas mais sistematizadas da linguagem escrita, já nessa primeira etapa da educação básica. Assim, a compreensão desse professor a respeito das ocorrências inerentes ao processo formal de apropriação dessa modalidade de linguagem assume importância crucial para estabelecer as bases sob as quais a criança se relacionará com a linguagem escrita.

Neste sentido, e a fim de contribuir com a formação de professores da Educação Infantil para a Educação Inclusiva, da maneira perspectivada neste texto, o objetivo central foi o de descrever o modo como foi abordada a questão das dificuldades de aprendizagem e o impacto de um diagnóstico equivocado atribuído a uma criança em fase inicial de aprendizagem formal da escrita, nas discussões empreendidas em um dos encontros teórico-reflexivos, que caracte- 
rizam parte das atividades colaborativas consideradas no subprojeto "Compreensão acerca do diagnóstico clínico da Dislexia e seu impacto no futuro escolar da criança matriculada em classes de Pré II da Educação Infantil". ${ }^{2}$ Tal subprojeto foi desenvolvido em 2010, como uma das etapas e no âmbito de um projeto maior denominado "Despatologização da aprendizagem da escrita e educação inclusiva: reflexões e ações do professor de Educação Infantil", o qual se encontra ainda em desenvolvimento no ano de 2011.

\section{Desenvolvimento}

A realização deste trabalho foi subsidiada pelos procedimentos preconizados pela abordagem colaborativa (IBIAPINA, 2008). Com base em tais procedimentos, inicialmente foi realizado o delineamento das expectativas dos 43 professores de classes de Pré II, de dez escolas municipais de Educação Infantil de um município de médio porte do interior do Estado de São Paulo, com idade entre 23 a 49 anos, e tempo de exercício no magistério entre 02 anos e cinco meses e 21 anos, sobre a temática das dificuldades de aprendizagem, 0 que possibilitou a identificação dos aspectos por eles elencados como referencial para as atividades colaborativas previstas. Cabe esclarecer que o projeto anteriormente mencionado, do qual derivou este trabalho, contou com autorização do Comitê de Ética, bem como o consentimento dos professores envolvidos sobre a participação voluntária e a ciência acerca dos objetivos e ações previstas no projeto.

O delineamento proposto se deu por meio da realização de: 1) Um fórum presencial de discussão sobre a temática proposta, momento no qual foi eleita, pelos participantes, a necessidade de melhor compreensão acerca da Dislexia, dentre os demais aspectos que deveriam caracterizar o referencial inicial para as discussões posteriormente deflagradas nos encontros teóricoreflexivos propostos; 2) Realização de entrevista individual anterior ao desenvolvimento das atividades colaborativas previstas, com base em um roteiro cuja elaboração foi subsidiada pelas discussões realizadas no fórum de discussão presencial e pela literatura compulsada. A opção por esse procedimento foi atrelada à possibilidade de se obter dados fornecidos pelos próprios participantes a respeito do discurso pedagógico cotidiano que utilizam e que direciona a atuação no âmbito escolar, no que se refere às práticas de despatologização da aprendizagem da escrita. A valorização desse discurso foi considerada pertinente por se acreditar que a partir da reflexão sobre ele é que o professor teria condições de vislumbrar a possibilidade de ressignificação sobre tais práticas, se julgasse necessária. O roteiro utilizado nesta etapa inicial compreendeu questões acerca da: caracterização da compreensão dos participantes a respeito de seu papel na edificação da escola inclusiva e na promoção da aprendizagem; identificação de possíveis formas de patologização e de despatologização da aprendizagem da escrita por eles utilizadas, cotidianamente, com seus alunos; e apresentação de subsídios para a sistematização de ações referentes à despatologização da aprendizagem, por meio da compreensão dos aspectos inerentes ao processo de apropriação da linguagem escrita. 
Após tal delineamento, optou-se pela realização de encontros teóricoreflexivos com periodicidade quinzenal e sistemática, durante um semestre, para a discussão acerca dos aspectos destacados pelos participantes e que envolviam a temática das dificuldades de aprendizagem. Nesses encontros, foram discutidas questões acerca da compreensão sobre sujeito, linguagem, aprendizagem, saúde, linguagem escrita, significado atribuído ao erro na escrita, análise de produção textual, compreensão do diagnóstico do ponto de vista de abordagens clínicas e educacionais, o que também incluiu questões sobre a Dislexia. Tais encontros também se destinaram ao planejamento de práticas pedagógicas, posteriormente empreendidas pelos participantes conforme o contexto de atuação de cada um dos envolvidos, perpassadas pelos aspectos motivacionais, pela valorização da interação entre o professor e o aluno, pelo resgate da autoestima do professor e do aluno para a construção de uma relação mais positiva com a linguagem escrita e pelas práticas coletivas.

Dentre todos os aspectos discutidos nos encontros teórico-reflexivos realizados, a compreensão acerca das dificuldades de aprendizagem e o impacto de um diagnóstico equivocado atribuído a uma criança em fase inicial de aprendizagem formal da escrita, particularmente, a caracterização equivocada de quadros de Dislexia, foram os que mais mobilizaram os participantes, razão pela se optou pelo detalhamento, neste artigo, do modo como tais aspectos foram abordados, conforme proposto no objetivo anteriormente anunciado.

Os problemas que comprometem o desempenho escolar têm assumido grande destaque nas áreas clínica e educacional, a exemplo da Dislexia que, historicamente, tem sido interpretada sob diferentes perspectivas teóricas. Consequentemente, a compreensão a respeito da Dislexia tem sido determinada com base nas concepções de linguagem e aprendizagem adotadas em tais perspectivas.

Assim, compreender a Dislexia pressupõe discutir sobre a linguagem e sobre o processo de aprendizagem, bem como sobre os aspectos individuais, acadêmicos e sociais que perpassam tal processo, visto que o não aprender, mais do que uma questão escolar, se configura como uma questão social, frente ao forte impacto que esse diagnóstico imprime ao indivíduo, criança ou adulto, considerado disléxico, e que pode corroborar para a exclusão educacional e social desse indivíduo. Portanto, a maneira como o educador, que lida cotidianamente com as questões relativas ao não aprender interpreta os aspectos que comprometem o desempenho acadêmico de seus alunos é determinante para a implementação de ações que favoreçam a superação das dificuldades que se apresentam no decorrer do processo formal de apropriação da linguagem escrita. Desse modo, é imprescindível ao educador o acesso a conhecimentos atualizados que lhe permita a análise crítica sobre tal assunto, pois em uma época em que se preconiza uma escola acolhedora à diversidade de alunos e às singularidades de cada indivíduo, ao se propor à análise crítica desse e de outros tantos assuntos implicados na aprendizagem, o educador fortalece sua contribuição para a edificação da escola inclusiva. 
A formação de professores para a Educação Inclusiva: alguns aspectos de um trabalho colaborativo entre pesquisadores e professores da Educação Infantil

Nesse sentido, faz-se necessário proporcionar aos professores em serviço e aos futuros professores em formação inicial a atualização de conhecimentos relativos à Dislexia, com base em múltiplos enfoques teóricometodológicos; permitir a análise crítica e comparativa sobre tais enfoques; fornecer subsídios que contribuam para o levantamento de indicadores que evidenciem a natureza das dificuldades apresentadas pelo aluno para posterior comparação crítica com as dificuldades consideradas na literatura como pertinentes aos quadros de Dislexia, fomentar a relação entre a teoria e a prática acerca dos diferentes aspectos envolvidos na compreensão acerca da Dislexia que resulte na compreensão sobre a real natureza de tais dificuldades, em detrimento da compreensão patologizadora de aspectos inerentes ao processo de apropriação da escrita.

Assim, neste encontro teórico-reflexivo, em particular, foi proposto, com base nas ideias de Massi (2010), o estudo e reflexão sobre: a compreensão acerca da aprendizagem e da Dislexia sob o ponto de vista clínico e educacional, bem como as divergências presentes na conceituação de Dislexia; a caracterização da Dislexia, com base nos critérios de classificação e a relação com as singularidades do processo de apropriação da escrita; a atuação da equipe interdisciplinar no diagnóstico da Dislexia; os parâmetros e critérios de avaliação empregados com crianças consideradas disléxicas, bem como os equívocos identificados; as dificuldades relacionadas à leitura e à escrita; o diagnóstico diferencial entre dislexia e os transtornos de desenvolvimento da leitura e escrita; os aspectos metodológicos da alfabetização do aluno diagnosticado como sendo disléxico; os conceitos de apropriação da linguagem escrita correntes nas práticas pedagógicas atuais; e as formas de intervenção pedagógica no processo de ensino e de aprendizagem do aluno considerado disléxico, no que se refere aos procedimentos e orientações.

Tal discussão foi deflagrada por meio de:

- discussões dialogadas: os conteúdos foram trabalhados sob a forma de apresentação oral ilustrada por slides, transparências e vídeo. Os participantes foram incentivados a formular e a responder a questionamentos referentes aos aspectos abordados, de modo a relacionar tais conteúdos e discussões com a sua prática pedagógica cotidiana; e

- formação de grupos de trabalho: foram propostas dinâmicas de grupos voltadas à compreensão dos assuntos trabalhados; confecção de materiais, elaboração e discussão de casos; análise de textos didáticos; entre outros. Para o desenvolvimento desses procedimentos, diferentes recursos metodológicos foram empregados, tais como a utilização de atividades individuais, por meio da elaboração de casos com base em experiências individuais com crianças com dificuldades no processo de apropriação da linguagem escrita que envolvessem, de acordo com a compreensão dos professores participantes, casos de Dislexia e de distúrbios de aprendizagem ou, ainda, com dificuldades de aprendizagem somente; atividades em duplas para a análise de dois 
textos produzidos por crianças com ocorrências na escrita divergentes das normas convencionais e com comprometimento dos aspectos discursivos da escrita selecionados pelos próprios participantes; e atividades em grupo, por meio de leitura dirigida, debate e análise de produção textual.

Durante todo o processo reflexivo empreendido, os participantes utilizaram um diário de campo para o registro acerca da compreensão das temáticas discutidas e sobre as contribuições apontadas para a continuidade e ampliação das ações que envolvem o Projeto "Despatologização da aprendizagem da escrita e educação inclusiva: reflexões e ações do professor de Educação Infantil" e o subprojeto "Compreensão acerca do diagnóstico clínico da Dislexia e seu impacto no futuro escolar da criança matriculada em classes de Pré ll da Educação Infantil", anteriormente mencionados.

Cabe ressaltar que essa análise dos participantes, durante o percurso metodológico empreendido, foi considerada essencial para promover os ajustes necessários à consolidação da participação colaborativa autônoma e emancipatória, por parte de todos os envolvidos, tal como prevê a abordagem colaborativa.

Na sequência, são apresentados exemplos de recortes de trechos de comentários registrados pelos professores participantes no diário de campo:

Um novo 'olhar', uma nova reflexão para que eu possa direcionar com uma nova consciência e abordagem e assim tentar contribuir para formar cidadãos críticos e mais preparados para a nossa sociedade. Muito obrigada.

Gostei muito dos encontros sobre esse tema e penso que deveria ser trabalhado com todos os professores da escola ou mesmo da secretaria municipal.

Esse curso deveria ser estendido para mais professores, tenho certeza que a maioria não distingue Dislexia, DI. dificuldades de aprendizagem que não se caracterizam como doença.

Gostaria de parabenizar pela iniciativa e gostaria de pedir para que estes cursos sejam mais divulgados e que o publico alvo não seja tão limitado como costuma ser (professores e coordenadores).

Gostaria que fossem feitos com maior frequência e divulgação, abordando o maior número de pessoas (estudantes, estagiários).

Considero o trabalho realizado bastante importante, sério e comprometido. Com certeza acrescentou muito na nossa formação. A carga horária, embora bastante cansativa, nos deixou com a vontade de querer mais.

As informações trouxeram boas reflexões, no sentido de repensarmos nossa prática pedagógica. Tivemos a oportunidade de troca, de reconstrução. Assim atenderemos a todos com um novo olhar. 
A formação de professores para a Educação Inclusiva: alguns aspectos de um trabalho colaborativo entre pesquisadores e professores da Educação Infantil

Se o curso era para fazer-nos refletir, parabéns!

Agradeço pela oportunidade. Se possível, mais encontros!

Considero toda abordagem discutida ao longo do curso muito importante para minha prática pedagógica, através de uma abordagem teórica significativa e contextualizada com as dificuldades encontradas na sala de aula.

Os professores que ministraram o curso estão de parabéns quanto à dinamização e formas de abordagem.

Gostaria de poder receber mais material escrito para facilitar o nosso trabalho na unidade escolar.

Adorei todos os professores e a clareza como passaram em suas aulas, união e compromisso com a disciplina apresentada.

Embora os cursos tenham sido ótimos, não sei se foram muito proveitosos por conta do ritmo intenso, do cansaço.

Sugiro que sejam oferecidos outros cursos deste tipo e que a oferta de vagas seja maior.

Todos os professores contribuíram para a construção do (meu) conhecimento didático e consequentemente na prática.

\section{Alguns resultados e conclusões}

Diante da perspectiva de educação inclusiva e da sistematização, cada vez mais precoce, do processo formal de escolarização na primeira etapa da educação básica, torna-se imprescindível conhecer o modo como o professor que atua com a Educação Infantil compreende o processo de apropriação da escrita e as suas singularidades (em muitas situações interpretadas, equivocadamente, como manifestações de distúrbios de aprendizagem). Tal compreensão subsidiará futuras ações, por parte desse professor, voltadas à valorização da aprendizagem, em detrimento da atuação que reforça, em sala de aula, a "institucionalização invisível" daquelas crianças que, em razão do modo particular como se relacionam com a linguagem escrita, são rotuladas desde 0 início do processo formal de apropriação da escrita como sendo aquelas que apresentam características que, posteriormente, confirmarão, equivocadamente, os quadros de distúrbios de aprendizagem, de leitura e escrita ou de Dislexia.

O conhecimento desses professores acerca desses quadros também passa a ser relevante se for identificada a necessidade de preparação desse professor, que leciona na educação infantil e que tem lidado com a sistematização do ensino formal da escrita nessa etapa educacional, para lidar com a diversidade de alunos, bem como com a mudança de sua conduta, quanto à melhora da qualidade do processo de ensino e de aprendizagem, no que se refere à apropriação de conhecimentos sobre a escrita, se este profissional possibilitar aos seus alunos o acesso a condições favoráveis à aprendizagem dessa modalidade de linguagem. 
Neste sentido, foi possível a identificação, mediante os relatos decorrentes da participação dos professores em serviço na educação infantil, registrados no diário de campo, da necessidade de ressignificação de suas vivências e experiências didáticas para a sistematização de ações direcionadas ao enfrentamento, no contexto escolar, das dificuldades de aprendizagem apresentadas por parte dos alunos.

Cabe ressaltar que o diálogo estabelecido entre os participantes, durante a realização das atividades propostas, favoreceu uma maior compreensão sobre as singularidades que se fazem presentes no processo de apropriação da escrita, bem como sobre o impacto das ações e intervenções do professor no processo de aprendizagem de seus alunos, de modo geral, e, em particular, daqueles considerados como os que apresentam dificuldades em se apropriar dessa modalidade de linguagem.

Em consequência, a ressignificação sobre a prática cotidiana desses professores, no que tange à temática aqui apresentada e discutida, poderá contribuir para a despatologização do ambiente escolar em que atuam, na medida em que poderão auxiliar seus alunos na construção de uma relação mais positiva com a escrita, em detrimento da adoção de procedimentos rígidos e restritos que não consideram a relação de cada sujeito com a escrita e as singularidades presentes em tal relação.

\section{Referências}

ARANHA, M. S. F. Inclusão social e municipalização. In: MANZINI, E. J. (Org.). Educação Especial: temas atuais. Marília: Unesp Marília, 2000. p. 1-9.

BERBERIAN, A. P. Princípios norteadores da avaliação clínica fonoaudiológica de crianças consideradas portadoras de distúrbios de leitura e escrita. In: BERBERIAN, A. P.; MASSI, G. A.; GUARINELLO, A. C. Linguagem escrita: referenciais para a clínica fonoaudiológica. São Paulo: Plexus, 2003. p. 11-38.

Linguagem escrita no contexto da clínica fonoaudiológica. In: FERREIRA, L. P.; BEFFI-LOPES, D. M.; LIMONGI, S. C. O. (Org.). Tratado de Fonoaudiologia. São Paulo: Roca, 2004. p. 846-61.

BRASIL. Ministério da Educação. Secretaria da educação fundamental. Parâmetros Curriculares Nacionais: Língua Portuguesa. Brasília: A Secretaria, 1997.

EIZIRIK, M. F. Distorções perceptuais em situações educacionais: teoria e exemplos. Educação e Realidade, v. 9, p. 7-18, 1984.

GIROTO, C. R. M. A parceria entre o professor e o fonoaudiólogo: um caminho possível para a atuação com a linguagem escrita. Marília, 2006, 256 f. Tese. (Doutorado em Educação)-Faculdade de Filosofia e Ciências- Universidade Estadual Paulista, Marília, 2006. 
A formação de professores para a Educação Inclusiva: alguns aspectos de um trabalho colaborativo entre pesquisadores e professores da Educação Infantil

IBIAPINA, I. M. L. de M. Pesquisa colaborativa: investigação, formação e produção de conhecimentos. Brasília: Líber Livro, 2008.

MASSI, G. A. A. A dislexia em questão. 2. ed. São Paulo: Plexus, 2010. v.1. 252p.

MOYSÉS, M. A. A. A institucionalização invisível: crianças que não-aprendem-na-escola. Campinas, SP: Mercado de Letras, 2001.

MOYSÉS, M. A. A.; COLLARES, C. A. L. A história não contada dos distúrbios de aprendizagem. Cadernos Cedes, v. 28, p. 31-47, 1992.

OLIVEIRA, A. A. S.; LEITE, L. P. Escola inclusiva e as necessidades educativas especiais. In: MANZINI, E. J. (Org.). Educação Especial: temas atuais. Marília: UNESP Marília, 2000, p. 11-9.

OMOTE, S. A integração do deficiente: um pseudoproblema científico. Temas em Psicologia, n. 2, p. 55-62, 1995.

. Classes especiais: comentários à margem do texto de Torezan \& Caiado. Revista Brasileira de Educação Especial, v. 6, n. 1, p. 43-64, 2000.

ROSENTHAL, R.; JACOBSON, L. Profecias auto-realizadoras na sala de aula: as expectativas dos professores como determinantes não intencionais da capacidade intelectual dos alunos. In: PATTO, M. H. S. (Org.). Introdução à Psicologia Escolar. São Paulo: T. A. Queiróz, 1981. p. 258-295.

Notas

${ }_{1}^{1}$ Apresentado por Aranha (2000) como uma proposta técnico-científica fundamentada no conhecimento a respeito dos ganhos em desenvolvimento social e pessoal decorrentes da convivência na diversidade e sob o princípio da igualdade, que aponta para o acesso de todos a todas as oportunidades, incluindo o contexto educacional.

2 O Pré II da Educação Infantil corresponde atualmente ao 1ํ. Ano do Ensino Fundamental.

\section{Correspondência}

Claudia Regina Mosca Giroto - Rua André Martins Parra, 250, Condomínio Vila Flora, Casa 91, CEP: 17.514-260, Marília, São Paulo, Brasil.

E-mail: claudia.mosca@marilia.unesp.br

Rosane Michelli de Castro - Rua Ângelo Seleghin, 887, Bairro Parati, CEP: 17.519-420, Marília, São Paulo, Brasil.

E-mail: rosanemichelli@marilia.unesp.br

Recebido em 03 de junho de 2011

Aprovado em 31 de agosto de 2011 